\title{
Understanding the Effects of Marriage and Divorce on Financial Investments \\ The Role of Background Risk Sharing
}

Christiansen, Charlotte; Joensen, Juanna Schröter; Rangvid, Jesper

\author{
Document Version \\ Published in: \\ Economic Inquiry \\ DOI: \\ 10.1111/ecin. 12113 \\ Publication date: \\ 2015 \\ License \\ Unspecified
}

Accepted author manuscript

Citation for published version (APA):

Christiansen, C., Joensen, J. S., \& Rangvid, J. (2015). Understanding the Effects of Marriage and Divorce on Financial Investments: The Role of Background Risk Sharing. Economic Inquiry, 53(1), 431-447. https://doi.org/10.1111/ecin.12113

Link to publication in CBS Research Portal

\section{General rights}

Copyright and moral rights for the publications made accessible in the public portal are retained by the authors and/or other copyright owners and it is a condition of accessing publications that users recognise and abide by the legal requirements associated with these rights.

\section{Take down policy}

If you believe that this document breaches copyright please contact us (research.lib@cbs.dk) providing details, and we will remove access to the work immediately and investigate your claim. 


\section{Understanding the Effects of Marriage and Divorce on Financial Investments: The Role of Background Risk Sharing}

Charlotte Christiansen, Juanna Schröter Joensen, and Jesper Rangvid

Journal article (Post print version)

This is the peer reviewed version of the following article: Understanding the Effects

of Marriage and Divorce on Financial Investments : The Role of Background Risk

Sharing. / Christiansen, Charlotte; Joensen, Juanna Schröter; Rangvid, Jesper. In:

Economic Inquiry, Vol. 53, No. 1, 2015, p. 431-447, which has been published in final form at http://dx.doi.org/10.1111/ecin.12113.

This article may be used for non-commercial purposes in accordance with

Wiley Terms and Conditions for Self-Archiving.

Uploaded to Research@CBS: December 2016 


\title{
Understanding the Effects of Marriage and Divorce on Financial Investments: The Role of Background Risk Sharing
}

\author{
Charlotte Christiansen* \\ CREATES, Aarhus University \\ Juanna Schröter Joensen ${ }^{\S}$ \\ Stockholm School of Economics \\ Jesper Rangvid ${ }^{\ddagger}$ \\ Copenhagen Business School
}

November 19, 2013

\footnotetext{
${ }^{*}$ CREATES, Department of Economics and Business, School of Business and Social Sciences, Aarhus University, Fuglesangs Alle 4, 8210 Aarhus V, Denmark, +45 87165576 (phone), cchristiansen@creates.au.dk.

$\S$ Department of Economics, Stockholm School of Economics, Sveavägen 65, Box 6501, SE 11383 Stockholm, Sweden, +46 (8) 7369263 (phone), Juanna.Joensen@hhs.se.

${ }^{\ddagger}$ Department of Finance, Copenhagen Business School, Solbjerg Plads 3, 2000 Frederiksberg, Denmark, +45 38153615 (phone), jr.fi@cbs.dk.

Christiansen acknowledges financial support from the Danish Council for Independent Research, Social Sciences and CREATES funded by the Danish National Research Foundation (DNRF78). Joensen acknowledges financial support from Jan Wallanders and Tom Hedelius stiftelse. The authors thank Manuel F. Bagues (discussant) and other participants at the Conference on Household Finance and Macroeconomics at Banco de España as well as Enrichetta Ravina (discussant) and other participants at the Annual Meeting of the European Finance Associations in Stockholm for useful comments.
} 


\title{
Understanding the Effects of Marriage and Divorce on Financial Investments: The Role of Background Risk Sharing
}

\begin{abstract}
We investigate how changes in marital status affect financial investments and how these effects vary with background risk. We use detailed register based panel data and difference-in-differences estimators to benchmark common unobserved influences on financial investments. Women increase the fraction of wealth invested in stocks after marriage and decrease it after divorce, whereas men show the opposite behavior. Households whose joint labor income risk is reduced more by marriage have a higher increase in their exposure to risky assets in marriage. Thus income risk sharing in the household is important for financial risk-taking and investment responses to marital transitions.
\end{abstract}

Keywords: Gender; Marriage and Divorce; Stock Market Participation; Portfolio Choice; Labor Income Risk Sharing

JEL Classifications: G11, J12, J16, D14 


\section{Introduction}

Do marital transitions - getting married or divorced - affect portfolio allocations? Do they affect men and women differently? And do changes in background risks associated with marital transitions influence any such effects? We provide answers to these questions by investigating the causal effect of changes in marital status on the portfolio decisions of men and women using a very detailed panel data set, taking into account changes in the labor income risk profile of the household associated with marital transitions.

It is well-known from the household finance literature that women tend to make less risky financial investments than men, differences between men and women are more pronounced for single investors, and married investors take on more risk than single investors. For instance, Sunden and Surette (1998), Agnew, Balduzzi and Sunden (2003), and Jianakoplos and Bernasek (1998) find that women, and in particular single women, hold less risky portfolios than men. Love (2010) and Bertocchi, Brunetti and Torricelli (2011) find that married investors (both men and women) hold more risky portfolios than single investors. Bertaut and Halliasos (1995), Bertaut (1998), and Guiso, Haliassos and Jappelli (2003) report that marriage increases stock market participation. ${ }^{1}$ We take this literature a step further by analyzing how investment responses across the two genders vary with marital transitions and background risk sharing in the household.

In the literature, the impact of gender and marital status on portfolio allocations is conventionally investigated by comparing one group of investors (e.g. single women) to the behavior of another group of investors (e.g. married women) at the same point in time, thereby providing an estimate of the difference between the financial portfolios of the average investor across different marital statuses. We depart from the conventional approach in two important aspects: First, we investigate whether investment responses are homogeneous across groups of investors or whether they are heterogeneous depending upon the degree of changes in background risks occurring when marital status changes. We do so by evaluating whether couples with highly correlated income processes behave differently than couples whose income processes are less correlated. We do so because we are concerned that the average difference between different groups of investors will not reveal the heterogeneity in the effects of marital changes

\footnotetext{
${ }^{1}$ Other papers, not focusing on gender differences or the impact of marital status but nevertheless including a gender or marriage dummy, find it to be significantly and positively related to stock market participation and/or the riskiness of the financial portfolio; see e.g. Guiso and Jappelli (2005), Guiso, Sapienza and Zingales (2008), and Van Rooij, Lusardi and Alessie (2007). In their seminal paper, Barber and Odean (2001) provide evidence that single young men trade more in risky assets, and conclude that men are overconfident.
} 
on financial portfolios if such effects vary across investors as a result of differences in background risks. While income risk has been shown to be important for portfolio allocation decisions (Bodie, Merton and Samuelson (1992), Viceira (2001), and Cocco, Gomes and Maenhout (2005)), empirical evidence using micro data is scarce. To the best of our knowledge, this is the first paper to consider the role of income risk sharing in the household on individual investment responses to marital transitions.

A second contribution of our paper relates to the empirical strategy we apply. The current literature compares groups of investors at the same point in time. One potential concern with such static cross-gender or cross-marital status estimators is that single investors might differ from married investors in unobserved systematic ways such that unobserved differences influence both the marriage propensity and the portfolio allocation. To tackle this concern, we use an empirical strategy that allows us to identify the causal effects of changes in marital status on portfolio choices of men and women. We compare the changes in the financial portfolio of the same investor over time (i.e. before and after marriage/divorce) while controlling for any common influences by benchmarking to similar investors not changing marital status. We thereby take systematic unobserved factors affecting these groups of investors similarly over time into account. Thus we isolate the causal effect of changes in marital status on financial investments using a difference-in-differences (DID) estimation strategy, where the implicit identifying assumption is that the portfolio choices of those making a marital transition would have been the same as the portfolio choices of those not making this transition if they had not made a marital transition. We use a very detailed register based panel data set consisting of a random sample of $10 \%$ of the Danish adult population for the period $1997-2003$. We focus on those investors who get married $(\approx 143,000)$ or divorced $(\approx 89,000)$ during the sample period, and compare their behavior with those investors who stay single $(\approx 370,000)$ or married $(\approx 850,000)$, respectively.

First, we present estimates of the average portfolio choice response to marital transitions for those making the transition. We examine whether this average response differs between men and women. We analyze both the stock market participation decision and the proportion of stocks in the financial wealth portfolio (denoted the risky share), once participating in the stock market. We find that marriage causes men to reduce the fraction of wealth held in stocks, whereas divorce increases this fraction. For women, it is the other way around: The effect of marriage on the risky share is positive (but insignificant), whereas divorce makes women reduce the risky share. Regarding participation in the stock market, we find that marriage makes both men and women participate more in the stock market. We thus provide causal evidence that single women take on less financial risk than married women, single men take on more 
financial risk than married men, and marriage makes both men and women participate more on the stock market.

Second, we evaluate whether these average effects depend on the changes in background risks that occur as a result of changes in marital status. Pooling of labor income risks between the two partners in a household may influence the total household labor income risk profile. Basically, the more correlated the income streams are, the less insurance is provided by the spouse for negative income shocks, i.e. those marrying (divorcing) someone with highly correlated income risk is getting a smaller increase (decrease) in insurance. Therefore, we expect these investors to make smaller changes to the risk composition of their portfolios. To assess the importance of this household risk sharing, we estimate labor income processes and average over education groups to deal with potential endogeneity of partnership formation and dissolution. We find that the effects depend on the degree of income risk sharing in accordance with theoretical predictions. Regarding stock market participation, we find that investors with highly correlated income processes change their stock market participation less after marital changes, i.e. increase their participation less after marriage, and decrease it less after divorce. We also find that the risky share in the financial portfolio depends on risk sharing: Investors with highly correlated income processes in the household have smaller financial investment responses to marital status transitions - sometimes the estimated response is even insignificant. We thus conclude that it is pivotal to account for risk sharing in the household when considering financial investment responses, as investors who provide each other with more labor income risk diversification respond significantly more to marital status transitions.

We conduct a number of robustness tests. Importantly, we analyze both what happens when investors get formally married and when they start cohabiting without being formally married. There are no significant differences in the investment responses of cohabiting and lawfully married investors. This is a novel result as previous research does not make this distinction, and typically only includes lawfully married investors in the analysis.

Our paper is closely related to Love (2010) but the analysis departs in important ways. First, we relate our findings on gender differences in investment responses to differences in background risks, thereby allowing for heterogeneous responses across investors with the same gender and marital status depending on the degree of income insurance provided by the household. Second, we use a different estimation strategy in that we focus on changes in portfolio holdings of the same investor over time and compare the decisions of the investors who change marital status to decisions of investors 
who do not. Thus, our estimation strategy helps us getting closer to identifying the causal effect of changes in civil status on portfolio decision as it controls for any common unobservable differences across groups. Third, we analyze both the risky share and the decision to participate in the stock market whereas Love (2010) exclusively models the risky share decision. Fourth, Love (2010) provides a theoretical model of demographics that is largely consistent with the empirical findings in our paper. Fifth, we observe individuals' complete civil status transitions and are also able to distinguish between being legally married and cohabiting. This allows us to get around non-random measurement error issues from potential misclassification and misrepresentation of individual civil status histories.

The remainder of the paper is organized as follows. Section 2 provides some theoretical considerations. Section 3 describes the data. Section 4 explains the DID estimation strategy. Section 5 presents our basic results. Section 6 investigates further the effects of household income risk sharing. Section 7 looks closer at our identifying assumptions. Section 8 contains further insights. Finally, Section 9 concludes. Various details are delegated to the accompanying Appendix.

\section{Theoretical Considerations}

Marriage and divorce are expected to affect investments in risky assets mainly via their impact on investors' economic resources or household preferences. There might also be other channels at work, for instance learning while being married and effects arising due to credit market imperfections.

\subsection{Economic Resources}

We focus on two ways that changes in economic resources following marriage or divorce might affect investments in risky asset. First, marriage and divorce affect the labor income process. Labor income is risky. A marriage between two individuals whose income profiles are not perfectly correlated will make the joint household income less risky; see Hess (2004). As labor income is non-tradeable and impossible to insure on financial markets, a lower volatility of labor income makes the wealth portfolio less risky. In general, this implies that the fraction of wealth in risky financial assets increase. ${ }^{2}$ If the riskiness of the combined labor income profile of the household is reduced while being married, marriage might increase investments in risky assets. The strength of

\footnotetext{
${ }^{2}$ For instance, Viceira (2001), Bodie et al. (1992), and Cocco et al. (2005) find that a more risky labor income reduces the risky share in the optimal financial portfolio.
} 
this effect, therefore, will depend on the income correlation between the individuals in the household. Hence, we expect both men and women to increase their participation rate in the stock market and their risky share after marriage, holding everything else constant, but most importantly, we expect this effect to be stronger for couples with less correlated income processes. On the other hand, divorce should reduce investments in risky assets of both men and women, and less so the larger is the income correlation between the individuals in the household.

Second, marriage affects the costs of running a household due to economies of scale; see e.g. Blow, Browning and Ejrnaes (2009) or Weiss (1997) for a survey. As an example, consider a household with a car. The expenses of the car are shared with the partner while being married, whereas an individual living alone must bear the full cost. Everything else equal, a married individual therefore has the opportunity to save more. There is amble evidence that married individuals have higher savings and wealth than unmarried individuals (Guner and Knowles (2004); Zagorsky (2005)) and very different consumption streams too. Related, Love (2010) and Bertocchi et al. (2011) show that marriage and divorce influence portfolio allocations. Our contribution is to show that the effects are causal and that they depend on both gender and household income risk sharing. Finally, participation costs could play a role: If some investors cannot afford to enter the stock market due to fixed participation costs (Vissing-Jorgensen (2004)), marriage might introduce new investors to the stock market because of their higher wealth and savings after marriage. If economies of scales matter, we expect that both men and women increase their probability of making risky investments after marriage, and reduce it after divorce.

\subsection{Preferences}

Differences in risk preferences between men and women might also affect portfolio allocations as a result of marriage or divorce. Holding other factors constant, a higher degree of risk aversion implies a lower fraction of wealth invested in risky assets. So, if men are less risk averse, as suggested by Sunden and Surette (1998) and Jianakoplos and Bernasek (1998), single men would invest a higher fraction of their wealth in stocks and vice versa for women. How does marriage and divorce affect asset allocation via risk preferences? If married men and women are altruistic towards each other, they care not only about their own individual utility but also about their joint utility. To illustrate this: Assume that there are two agents in the household - a man and a woman - that are altruistic towards each other. Each agent $i$ maximizes social utility which is given by: $U_{i}(c)=u_{i}\left(c_{i}\right)+\alpha u_{j}\left(c_{j}\right)$, for $i, j=m, f, i \neq j$, where $0<\alpha<1$, since agents 
care for each others private utility, $u_{j}(\cdot)$. Abstracting from uninsurable background risks, the households' utility function will become a convex combination of the man's and the woman's. Hence, we expect that the man's portfolio would become less risky and the woman's portfolio will become more risky after marriage. The share invested in risky financial assets for each household member would now depend on the combination of risk aversion in the household and altruism, $\alpha$. After divorce, the effects should be reversed. Note that this effect should not be at play for same-sex partnership formations and dissolutions if the difference in risk preferences is mainly driven by gender-specific differences in risk preferences.

All hypotheses are collected in Table 1 (top). The hypothesized responses apply to both stock market participation and the risky share. In addition, the strengths of the responses might depend on labor income risk sharing, as described in the text above.

\section{Data}

We use a very rich register-based panel data set comprising a random $10 \%$ sample of the Danish population covering end-of-year data during the period 1997-2003. Some further details about the Danish institutional settings are available in the accompanying Appendix. The data stem from Statistics Denmark, which has gathered the data from different sources, mainly from administrative registers. Given that the data are register based and concern a large representative sample, the results are not influenced by selfselection biases. The scope and quality of the data are comparable to other studies using Scandinavian data such as Christiansen, Joensen and Rangvid (2008), Calvet, Campbell and Sodini (2007), Calvet, Campbell and Sodini (2009), Calvet and Sodini

(forthcoming), Massa and Simonov (2005), Grinblatt and Keloharju (2000), Grinblatt and Keloharju (2001), and Grinblatt, Keloharju and Linnainmaa (2012). We restrict the sample to individuals between 20 and 60 years old.

Table 2 provides summary statistics on the variables we use in this study. We show statistics for men and women separately. Moreover, the investors are divided into four groups. The first two groups comprise the basis for investigating the effects of marriage: investors who are single throughout the sample (212, 113 men and 157,333 women) and investors who get married during the sample period (77,464 men and 66,377 women). The definition of married investors includes both lawfully married and unmarried cohabiting couples, for further details see the Appendix. The last two groups comprise the basis for investigating the effects of divorce; investors who are married throughout (406, 957 men and 443, 209 women) and investors who divorce during the 
sample period (41,092 men and 47,455 women). Note that we restrict attention to individuals making at most one marital status transition during the sample period.

Investors who change marital status during the sample period are younger than investors who do not. Fewer men than women have children living at home. The income of men is higher than the income of women across marital status groups, and the income of married investors is generally higher than the income of single investors, with this difference being even more pronounced for men. We include an economist dummy in the regressions, as Christiansen et al. (2008) show that economists are more likely to hold stocks than investors with any other education; slightly more men are economists.

Stock holdings are the combined values of directly held stocks and stocks held indirectly via equity mutual funds at year end; Statistics Denmark does not separately report the direct holdings of stocks. Likewise, bond holdings are directly held bonds and bonds held indirectly via fixed income mutual funds. We investigate both the stock market participation decision and the risky share. We follow Brunnermeier and Nagel (2008), Calvet and Sodini (forthcoming), and Love (2010) and measure the risky share by the fraction of financial wealth held in stocks, i.e. stock holdings divided by financial wealth, where financial wealth is the sum of stock holdings, bond holdings, and cash. Doing so, we focus on liquid assets, and exclude real estate and pension contributions from the definition of "wealth".

The portfolio holdings of an investor remain with that investor - also after marriage - unless there is an active trade, i.e. there are no mechanical effects on the portfolio holdings arising from marriage.

The stock market participation rate varies between $16.6 \%$ and $29.6 \%$ with married investors participating more than single investors, and men participating more than women. The same goes for the riskiness of the investors' portfolios: Men invest a higher fraction of their financial wealth in stocks, and married investors also hold more risky portfolios.

The stylized facts of the Danish data are overall comparable to those in US data.

\section{Difference-in-Differences Estimation}

In the empirical analysis we focus on two outcome variables: stock market participation and the risky share. The outcome variable for individual $i$ at time $t$ is denoted $Y_{i t}$. Throughout, we employ the DID estimation strategy laid out in this section. 
When considering the effect of marriage we select all individuals who are single at the end of year $t-1$. Then we distinguish between those who are also single at the end of year $t$ and those who are married at the end of year $t$. We let $T_{j}=1$ for those individuals who get married at $t_{0} \in\{1998, \ldots, 2002\}$ and $T_{j}=0$ for the remaining individuals. ${ }^{3}$ We are interested in estimating the average effect on the outcome variable for the investors who get married: $E\left[Y_{i t}^{1}-Y_{i t}^{0} \mid T_{j}=1\right]$ for $t>t_{0}$, where $Y_{i t}^{1}$ is the outcome for investor $i$ at time $t$ when the investor is married and $Y_{i t}^{0}$ is the outcome the investor would have had if staying single. Since an investor's outcome cannot be observed both when the investor gets married and does not get married, the central problem of evaluating this effect is the construction of counterfactuals.

The simple DID estimator compares the change in the outcome variable for investors who get married with the change in the outcome variable for investors who stay single. The implicit identifying assumption is that if none of the investors had married, the change in the outcome variable would have been the same for both groups of investors. ${ }^{4}$ The simple unconditional DID estimator is consequently calculated as:

$$
E\left[Y_{i, t>t_{0}}^{1}-Y_{i, t<t_{0}}^{0} \mid T_{j}=1\right]-E\left[Y_{i, t>t_{0}}^{0}-Y_{i, t<t_{0}}^{0} \mid T_{j}=0\right] .
$$

We also control for additional background variables using a regression framework to generalize specification (1). Let After ${ }_{i t}=\mathbf{1}\left[t>t_{0}\right]$ denote the indicator of whether the observation is after the individual married. The DID estimator of the effect of marriage is the estimated coefficient $\left(\gamma_{D I D}\right)$ to $A f t e r_{i t} * T_{j}$ in the following OLS regression of the outcome variable $Y_{i t}$ on $T_{j}$, After tit $\cdot T_{j}$, and various additional control variables; see e.g. Heckman, LaLonde and Smith (1999) for details:

$$
Y_{i t}=\gamma_{0}+\gamma_{1} T_{j}+\gamma_{D I D} \text { After }{ }_{i t} \cdot T_{j}+d_{t}+X_{i t} \delta+\epsilon_{i j t}
$$

where $d_{t}$ denotes year-specific controls, $X_{i t}$ is the vector of additional control variables, and $\epsilon_{i j t} \sim N\left(0, \sigma^{2}\right)$ is the unobserved idiosyncratic variation in outcomes across individuals, year, and marriage group. One potential problem - with no straightforward solution - is if some of this variation is common to individuals in the same year and

\footnotetext{
${ }^{3}$ The earliest changes in marital status that we consider pertain to 1998 (the second year of the sample) such that we have observations for the year before the change. Similarly, the latest changes in marital status happen in 2002 (the penultimate year of the sample) such that we have observations for the year after the change.

${ }^{4}$ Formally, this identifying assumption is $E\left[Y_{i, t>t_{0}}^{0}-Y_{i, t<t_{0}}^{0} \mid T_{j}=1\right]=E\left[Y_{i, t>t_{0}}^{0}-Y_{i, t<t_{0}}^{0} \mid T_{j}=0\right]$. This assumption cannot be tested directly since $Y_{i, t>t_{0}}^{0}$ is unobserved for $T_{j}=1$. However, we establish the credibility of this "common trends" assumption in Section 7.2 by testing whether there are any marriage group-specific trends.
} 
marriage group; e.g. $\epsilon_{i j t}=u_{j t}+\varepsilon_{i j t}$. To accommodate the inference problem arising in the presence of marriage-year specific random effects, $u_{j t}$, we present two kinds of standard errors: First, assuming $\epsilon_{i j t}$ are i.i.d., OLS standard errors provide valid inference. Second, assuming errors are independent across years and marriage groups; thus clustering standard errors by marriage and year $\left(T_{j} \times t\right)$ generates valid inference. ${ }^{5}$

Two comments about the empirical specification: First, we use group fixed effects and not individual fixed effects. Some of our main control variables have little (or no variation) over time. For instance, the level and field of education changes very little over time. Similarly, the household income correlations are fixed over time for each individual. Therefore, the partial effects of these control variables would not be very precisely estimated if we used an individual fixed effects model. However, we corroborate that our main conclusions are robust to estimating our baseline specification with individual fixed effects. Second, we assume that investments are uncorrelated over time. We recognize, however, that people can hold assets over multiple years, and that serial correlation therefore could be a potential concern. A solution could be to cluster errors on the marriage group level as this would allow for arbitrary correlation over time within groups, thus also for arbitrary correlation of standard errors for individuals over time. However, we can not rely on standard asymptotic results for clustering with only two marriage groups. Instead, in robustness tests, we cluster errors on the individual level. Our main conclusions remain valid.

\subsection{Stock Market Participation}

First, the outcome variable is the stock market participation $\left(Y_{i t}=S_{i t}\right)$. At the end of each year $t$ we observe the amount held in stocks by individual $i$, denoted by $S_{i t}^{*}$, $i=1, \ldots, N$ and $t=1, \ldots, T_{j}$. We focus on the binary choice variable $S_{i t}=\mathbf{1}\left[S_{i t}^{*}>0\right]$, where $S_{i t}$ is an indicator for participation in the stock market of individual $i$ at time $t$.

For robustness, we also estimate the corresponding probit model to take into account that the participation variable is binary.

\footnotetext{
${ }^{5}$ See Angrist and Pischke (2008) for a more detailed discussion of these issues. We do not allow for arbitrary correlations in errors within marriage groups clustering by marriage. This should in principle generate valid inference in the case of serial correlation in the random effects. Yet, the caveat is that we only have two clusters and valid inference relies on having a large number of clusters (and not only on cluster size).
} 


\subsection{Portfolio Riskiness}

Second, the outcome variable is the risky share $\left(Y_{i t}=\frac{S_{i t}^{*}}{W_{i t}}\right)$. We use the proportion of financial wealth invested in stocks, $\frac{S_{i t}^{*}}{W_{i t}}$ to measure the portfolio riskiness like in e.g. Brunnermeier and Nagel (2008), Calvet and Sodini (forthcoming), and Love (2010). The first set of DID estimates for the risky share is based only on individuals participating in the stock market.

We also correct for censoring of the risky share arising from limited stock market participation using the equivalent tobit estimates instead of the OLS estimates of (2) for those participating. Comparing the OLS and tobit estimates we can evaluate whether it is important to account for limited stock market participation.

\subsection{Control Variables}

We use a standard set of control variables in the analyses. We expand the regressions in multiple steps, adding additional control variables in each step in order to see whether some of the control variables have particular effects on the results. In specification (i) we include year indicators. In specification (ii) we also include age, an indicator for children living at home, the length of education, and an indicator for economics education. In specification (iii) we add log non-financial income. In specification (iv) we add financial wealth.

\section{Average Responses of Men and Women}

We structure the discussion so that we first present the results and afterwards discuss how they can be interpreted in relation to the hypotheses laid out in Section 2.

\subsection{Participation Results}

Table 3 presents the DID estimates of the change in the stock market participation rate due to marriage and divorce. We find that marriage increases the stock market participation rate for men. In order to explain the estimates, consider specification (ii) where the DID estimator is 0.011 . This implies that the average increase in participation rate due to marriage is 1.1 percentage points. The 1.1 percentage points can be compared to the overall unconditional rate of stock market participation of $20 \%$ for men staying single. Marriage also increases the stock market participation rate of women. In addition, the effect of marriage is larger for women than for men: According to specification 
(ii) marriage increase the participation probability of women by 1.8 percentage points.

Divorce decreases the stock market participation rate for men by 1.6 percentage points in specification (ii). On the other hand, divorce increases women's participation rate by 1.9 percentage points.

Overall, the inference is neither affected by adding control variables, choice of standard errors, nor by estimation method.

\subsection{Risky Share Results}

In Table 4, we show the results from the DID estimations for the fraction of financial wealth held in stocks. The main point to notice is that marriage makes men invest less risky. The effect of marriage on the risky share held by women is positive, but insignificant. Hence, for men, marriage acts as a "risk-reducer" whereas marriage acts as a weak "risk-increaser" for women. More specifically, we see in model (ii) that on average marriage decreases men's risky share by 1.4 percentage points. On the other hand, divorce decreases men's risky shares by 1.8 percentage points, whereas for women divorce reduces their risky share by 4.2 percentage points.

Overall, inference is not sensitive to adding more control variables and whether based upon OLS or clustered standard errors. We also note that there are only minor differences between the DID estimates from OLS and tobit models. This means that it is not qualitatively important to account for the stock market participation decision when analyzing how portfolio riskiness changes because of marital status changes. The tobit model produces slightly smaller estimates in absolute terms, indicating stronger responses on the intensive margin for those already participating in the stock market.

\subsection{Interpretation of Results}

Marriage makes men participate more in the stock market, but hold less risky assets in their financial portfolio. Divorce makes men participate less in the stock market and hold more risky assets. On the other hand, marriage makes women participate more in the stock market and increases (not always significantly, though) the share in risky assets, whereas divorce makes women participate more but reduce their risky share. We collect the signs of the effects in Table 1 (bottom).

Concerning the risky share, the sign of the effects line up very well against those we expect. Financial allocations in two-headed households seem to reflect social preferences of the household - not decisions taken by individuals who invest on the basis of their 
private preferences only. Concerning stock market participation the results are mainly consistent with the effects stemming from economic resources: Marriage makes both men and women increase participation, as one would expect when economic resources are increased after marriage and there are fixed costs of stock market participation. Divorce makes men - but not women - reduce their participation rate, which could also be due to a reduction in economic resources. On this interpretation, we note that we have controlled for income in two empirical specifications. Hence, our results indicate that it is the freeing up of economic resource because of economies of scale during marriage which make investors participate more, and not changes in the individuals' level of income as such.

\section{Household Income Correlations}

To assess whether income insurance in the household affects the investment response to household transitions, we construct a measure of income correlation in the household. Following the literature on marriage formation and dissolution (Hess (2004) and Nielsen and Svarer (2009)) we deal with potential endogeneity bias from partner matching by basing our income correlation measure on information for all years and all individuals in the sample. Therefore we minimize the potential spurious correlation from using observed partners only as they affect each other's income processes. Individuals' income processes are defined by their educational group. Individuals are grouped into 23 mutually exclusive and exhaustive education groups. ${ }^{6}$ There are thus $23 \times 23$ possible partner matches. Our income measure is the residual from gender specific Mincer (1974) log non-financial income regressions on actual labor market experience and experience squared. The income correlation is then computed as the pooled time-series correlation between average income residuals. That is, a man in education group $k$ and a woman in education group $l$ have an income correlation defined by the correlation over time between the average income residuals for men with education $k$ and women with education $l$. By construction, the income correlation is the same for all couples with the same educational combination and singles have a zero income correlation. Individuals are then grouped according to the income correlation during marriage for all

\footnotetext{
${ }^{6}$ The 23 education groups are the following: compulsory schooling, high school, education, humanities/arts (short), humanities/arts (medium), humanities/arts (long), life sciences/fishing/defense/transport (short), life sciences/fishing/defense/transport (medium), life sciences/fishing/defense/transport (long), business/commercial (short), business/commercial (medium and long), social sciences (short), social sciences (medium), social sciences (long), health sciences (short), health sciences (medium), health sciences (long), natural science/tech (short), natural science/tech (medium), natural science/tech (long), economists (short), economists (medium), economists (long).
} 
individuals making a marital status transition.

The average income correlation is fairly large and positive at 0.55 with a large standard deviation of 0.34 . There are both large negative and large positive income correlations as they range from -0.64 (for women with a long education in life sciences/fishing/defense/transport and men with a long education in natural science/tech) to 0.99 (for women with a short education in economics and men in education).

Tables 5 and 6 show the results from taking the income correlation into account for the stock market participation and the risky share, respectively. We conduct the same DID estimations as above and add two additional explanatory variables, namely the income correlation itself, $\operatorname{Corr}_{f m}$, and its interaction with the DID interaction term, After $i t * T_{j} * \operatorname{Corr}_{f m}$, where $\operatorname{Corr}_{f m}$ denotes the correlation between the income process of say woman $i$ in education group $f$ and her education group $m$ husband's income process. Thus the last term is an interaction between this income correlation, whether the individual makes a marital transition, and whether the observation is in the period after this transition.

First, consider the results for stock market participation in Table 5. The coefficients to the income correlation itself are generally negative indicating that a higher income correlation reduces stock market participation. However, these estimates are mostly not statistically significant. On the other hand, the income correlation generally influences the stock market participation responses to marriage and divorce significantly. For example, consider the effect of marriage for men exemplified by specification (ii). Men who get married increase their participation rate by 3.8 percentage points compared to similar men not getting married. This can be compared to the response of 1.1 percentage points reported in Table 3. At the same time, however, a more positive income correlation reduces this average response. We find that the participation response is significantly lower for a man whose income is more correlated with that of his wife. Quantifying this difference: comparing two men where the correlation of the income of one of them with that of his wife is numerically one (1.0) higher than the income correlation the other man faces, the change in participation rate is 3.7 percentage points lower for the man whose income is highly correlated with that of his wife. This is an economically large effect. Hence, we find significant heterogeneity in participation responses depending on the riskiness of the joint household income process.

Concerning the rest of the results in Table 5, the table shows that the sign to the After $_{i t} * T_{j} * \operatorname{Corr}_{f m}$ coefficient generally is the opposite of the sign to the After ${ }_{i t} *$ $T_{j}$ coefficient. This means that both men and women increase their stock market participation after marriage and decrease it after divorce, however, those with a more 
correlated income process in the household have a smaller response, i.e. increase their participation less after marriage and decrease it less after divorce. In other words, labor income insurance works in the direction one would expect: If the income correlation is high, there is not a lot of income risk sharing taking place in the household after marriage, and these individuals increase their participation in the stock market to a smaller degree. However, if the income correlation is low the joint labor income process of the household is less risky than the labor income processes of the individuals, and individuals become more likely to take on stock market risk.

Consider now the results for the risky share in Table 6. We find that households with a higher income correlation in general hold less risky portfolios. Interestingly, however, controlling for this correlation seems to wash out the impact of the marital status transition on financial portfolio riskiness, as the coefficients to the two interacted variables $\left(\right.$ After $_{i t} * T_{j} * \operatorname{Corr}_{f m}$ and $A f t e r_{i t} * T_{j}$ ) are generally insignificant, except for men after divorce: men increase their risky share upon divorce - less so if exiting a marriage with a higher income correlation. We thus still observe the tendency that men decrease the riskiness of their portfolios upon marriage, whereas women increase their risky share upon marriage and decrease it upon divorce, however, having a highly correlated income in the household counteracts these changes in riskiness upon the household transition, and even make several of them insignificant.

\section{Identifying Assumptions and Specification Tests}

We compare the choices of those individuals who change marital status (the treatment group) with the choices of those who do not change marital status (the control group). As it is not possible to observe what the individuals in the treatment group would have done, had they not been treated, we can instead illustrate how the individuals in the control group compare with those that were treated late respectively early in the sample period. The idea is that if the dynamics of responses of those being treated late differ from the responses of the individuals in the control group, the identifying assumptions of those getting treated might be problematic. In this section, we first illustrate graphically the robustness of the identifying assumptions, then we present the results from formal specification tests.

\subsection{Graphical Illustrations}

Figure 1a shows the stock market participation rate of those men who stay single during the whole sample period, those who get married early in the sample period, and those 
who get married late in the sample period. There are some noteworthy patterns: For all three groups of individuals, the participation rate increases over time. However, the participation rate of those who get married early in the sample period increases more than the participation rate of those who stay single during the sample period, and it also increases more than the participation rate of those who get married late in the sample period. In itself, this indicates a positive impact on stock market participation from getting married. ${ }^{7}$ But are those investors different from those investors not getting married? We can get a sense of this by comparing the dynamics of the participation rates of the investors in the control group (those who stay single) and the investors getting married late in the sample period. These trends are almost identical, indicating that individuals who stay single do not behave differently from singles who marry. In other words, the common trends identifying assumption looks reasonable.

Figures $1 \mathrm{~b}, 1 \mathrm{c}$, and $1 \mathrm{~d}$ are structured in the same way. Figure $1 \mathrm{~b}$ concerns women who get married, 1c men who get divorced, and 1d women who get divorced. The trends in the stock market participation rate of those who get treated late and the control group are more or less parallel, i.e. the identifying assumptions are reasonable.

Figure 2 describes the same patterns for the risky share. The trends in risky share for the late-treatment and control group are parallel. Second, Figure 2 also illustrates that there is a clear spike in risky share around year 2000 associated with the stock market boom up until 2000 and the drop after 2001.

Overall, we find no need to worry about the identifying assumptions being reasonable. ${ }^{8}$ We can test the credibility of the identifying assumption that the change in financial market behavior would have been the same for the treatment as the control group, had there been no change in marital status for the treatment group: First, we test the common trend assumption. Second, we get at the exogeneity assumption.

\subsection{Group Specific Trends}

We test for common trends in the treatment and control group by extending the DID regressions with the following variable: $T_{j} * t$, where $t$ is simply the year of the observation. If the identifying assumption holds, then $T_{j} * t$ is insignificant. The results using the subgroup of investors who change marital status in 2002 are available upon request. We accept the null hypotheses in most cases. Reassuringly, for those investors in the treatment group that we observe for the longest time before changing marital status,

\footnotetext{
${ }^{7}$ We also find a similar pattern when controlling for background characteristics.

${ }^{8}$ This is also corroborated examining the time patterns of income and wealth across groups.
} 
we cannot reject that the identifying assumption of common trends is satisfied.

\subsection{No Anticipatory Effects}

Do investors change marital status because they anticipate that this will lead to a change in their exposure to the stock market? Hence, we would like to test for reverse causality to assess whether the effects we identify run from changes in marital status to financial market behavior, and not vice versa. We test whether the results are driven by anticipatory effects by including leads of After $_{i t} * T_{j}$ in the regressions. The leads of After $_{i t} * T_{j}$ should be insignificant if there are no anticipatory effects. The results using the subgroup of investors who change marital status in 2002 are available upon request. The null hypothesis that marital status transitions are exogenous cannot be rejected, as the leads are insignificant. Hence, we conclude that changes in marital status do not occur because individuals anticipate that it will change their stock market behavior, but that the changes in financial market behavior we observe can be attributed to the change in marital status.

\subsection{Time Patterns}

In the final specification test we include lags of $A f t e r_{i t} * T_{j}$ in the DID regressions. The pattern of the estimated coefficients to these lags inform us on changes over time in the effects on financial market behavior resulting from changes in marital status, for instance whether there is learning going on such that the effects become stronger or weaker over time. We conduct this analysis for those investors who change marital status early in the sample (1998) (results available upon request). The lagged effects are not significant for the stock market participation estimations. For the risky share, the lagged effects are not significant for marriage. For divorce, however, there is some significant time patterns. For men, the second lag is significantly positive, which indicates that men invest more risky already the year following the divorce. For women, the change in risky share is after two years. So, the change in risky share brought about by divorce takes place with a slight lag.

Overall, the results from this section demonstrate that our identifying assumptions hold implying that the main event triggering differences in portfolio allocations around changes in marital status is the change in marital status. The implication of this is that

the effects on portfolio allocations from change in marital status that we have estimated can plausibly be considered causal relationships. 


\section{Further Insights}

\subsection{Remaining Control Variables}

The estimated coefficients to the other control variables in the participation models are in line with the stock market participation literature: ${ }^{9}$ Stock market participation is positively influenced by income, wealth, the level of education, age, and being an economist. Stock market participation is negatively influenced by children. These qualitative conclusions are independent of whether we look at investors who get married or divorced, or whether we look at men or women. Similarly for the risky share.

\subsection{Age}

To investigate further whether age plays a role for the effects of changes in marital status on financial market behavior, we now interact $A f t e r_{i t} * T_{j}$ with age. The interaction terms are generally very small compared to the DID estimators (and often insignificant). Hence, we conclude that the effects of changes in marital status on financial market behavior are independent of the age of the investor experiencing the change in marital status.

\subsection{Definition of Marriage}

Our definition of married investors includes both lawfully married and unmarried cohabiting couples. In order to test whether there is a difference between the investment responses of those starting cohabiting and those getting married, we estimate the effects on stock market participation and risky share when investors change civil status from cohabiting to being lawfully married. We find no significant effects on investment behavior. Thus, we find that empirically it is unimportant to distinguish between cohabiting and lawfully married investors when analyzing investment responses to changes in family status. We emphasize that this finding is novel in itself, as previous studies do not distinguish between lawful marriage and cohabitation, and typically only include lawfully married in the definition of marriage.

\subsection{The Role of Education}

We investigate the role of education in two ways.

\footnotetext{
${ }^{9}$ All results of this section are available upon request.
} 
First, we investigate the role of investors having an economics education as this is known to be important for investors' stock market participation decisions, cf. Christiansen et al. (2008). Economists have acquired information about financial markets and risk-return trade-offs through formal education. Thus examining the effects for economists allows us to examine whether more information and learning are important. We find that the effects of marriage and divorce upon stock market participation and the risky share is generally of smaller magnitude than the effect for other investors. This means that for investors who are educated in economics and thereby have knowledge about the stock market, the financial decisions are taken more independently from their spouses.

Second, we also investigate the role of education by interacting $A f t e r_{i t} * T_{j}$ with the length of education of the investor. The estimated education interactions are very small compared to the DID estimators themselves and are often insignificant. Education does not seem to influence the results we have reported above. So, the changes in financial behavior in relation to changes in marital status appear independent of length of education. However, the type of education is important as stressed in the discussion of economists above.

\subsection{Stock Market Drop}

From its peak in late 2000, the Danish stock market dropped by around $30 \%$ in late 2001. It is possible that this could cause some investors who change marital status after the drop in the stock market (i.e. after 2001) to behave differently than other investors. To see whether this is the case, we estimate separate DID models for investors changing marital status in 1999 and 2002. It is evident that the DID estimates lead to

similar conclusions when considering 1999 and 2002 changes in marital status (except for divorcing women's risky share). Thus, the 2000-2001 stock market drop does not seem to have influenced the effects of marriage and divorce upon investors' financial decisions.

\subsection{Same-Gender Marriage}

We consider marriage and divorce of same-gender investors. As there are few samegender marriages and divorces (only around 1,000), the results should be interpreted with caution. The DID estimators are never significant which indicates that samegender marriage and divorce have no effects upon stock market behavior. This is tentative evidence that the changes brought about by marriage and divorce are driven 
by gender-specific differences in risk aversion.

\section{Conclusion}

Using a very comprehensive panel data set, we investigate how changes in marital status affect stock market investment behavior of men and women with respect to their stock market participation and risky share. We find that marriage causes men to reduce the fraction of wealth they hold in risky assets (indicating that marriage makes men invest less risky), whereas they increase risk after divorce. For women, it is the other way around. Hence, marriage acts as a financial "risk-reducer" for men and a financial "risk-increaser" for women. While living together, financial decisions are adjusted towards reflecting the preferences of the partner. We also study how changes in marital status affect the likelihood of holding stocks. Here we find that both men and women increase their participation rate after marriage, whereas men reduce their rate of participation after divorce, though women do not. This indicates that marriage frees up economic resources and therefore makes individuals more likely to pay the stock market participation costs.

It could be interesting to open the black box of how couples make financial investment decisions, as well as what determines the differences in background risks. For instance, learning about risky assets can affect the tendency to take on financial risk: If single men are more willing to take on financial risk (perhaps because of lower risk aversion, as mentioned above), men learn more about the characteristics of risky financial assets while being single. While being married, the woman might learn about risky assets from her husband; Hong, Kubik and Stein (2004) show how learning from peers affect financial risk taking of individuals, and Christiansen et al. (2008) show how learning from a spouse with an economics education increases stock market participation. Another effect might arise from credit market imperfections. When credit markets are imperfect, an economic reason to marry could be to extend credit by coordinating investments. The pooling of income, information, and other resources as well as risk sharing and bargaining in the household complicates this issue. ${ }^{10}$ Bargaining power and division of labor in the household, e.g. to exploit comparative advantages, may further alter the labor supply, hence the labor income, of each of the individuals in the household. Basically, a full analysis of these issues has to both quantify the gains of marriage and take a stance on how these gains are distributed in the household. ${ }^{11}$ We

\footnotetext{
${ }^{10}$ See e.g. Weiss (1997) for a survey on the economic reasons for marriage, how families solve their economic problems, and the economic consequences of divorce.

${ }^{11}$ Thornqvist and Vardardottir (2012) give an interesting first attempt to shed light on some of these
} 
leave these interesting extensions to future work.

\section{References}

Agnew, J., Balduzzi, P. and Sunden, A.: 2003, Portfolio Choice and Trading in a Large 401(k) Plan, American Economic Review 93(1), 193-215.

Angrist, J. D. and Pischke, J. S.: 2008, Mostly Harmless Econometrics: An Empiricists Companion, Princeton University Press.

Barber, B. M. and Odean, T.: 2001, Boys will be Boys: Gender, Overconfidence, and Common Stock Investments, Quarterly Journal of Economics 116(1), 261-289.

Bertaut, C.: 1998, Stockholding Behavior of U.S. Households: Evidence from the 1983-1989 Survey of Consumer Finances, Review of Economics and Statistics $\mathbf{8 0}(2), 263-275$.

Bertaut, C. and Halliasos, M.: 1995, Why do so Few Hold Stocks?, Economic Journal 105(432), 1110-1129.

Bertocchi, G., Brunetti, M. and Torricelli, C.: 2011, Marriage and Other Risky Assets: A Portfolio Approach, Journal of Banking and Finance 35, 2902-2915.

Blow, L., Browning, M. and Ejrnaes, M.: 2009, Marriage and Consumption, Working paper, University of Oxford.

Bodie, Z., Merton, R. and Samuelson, P.: 1992, Labor Supply Flexibility and Portfolio Choice in a Life-Cycle Model, Journal of Economic Dynamics and Control 16(34), 427-449.

Brunnermeier, M. and Nagel, S.: 2008, Do Wealth Fluctuations Generate Time-Varying Risk Aversion? Micro-Evidence on Individuals' Asset Allocation, American Economic Review 93(3), 713-736.

Calvet, Campbell and Sodini: 2007, Down or Out: Assessing the Welfare Costs of Household Investment Mistakes, Journal of Political Economy 115, 707-747.

Calvet, Campbell and Sodini: 2009, Fight or Flight? Portfolio Rebalancing by Individual Investors, Quarterly Journal of Economics 124, 301-348.

issues. 
Calvet, L. and Sodini, L.: forthcoming, Twin Picks: Disentangling the Determinants of Risk-Taking in Household Portfolios, Journal of Finance .

Christiansen, C., Joensen, J. S. and Rangvid, J.: 2008, Are Economists more Likely to Hold Stocks?, Review of Finance 12(3), 465-496.

Cocco, J., Gomes, F. and Maenhout, P.: 2005, Consumption and Portfolio Choice Over the Life-Cycle, Review of Financial Studies 18(2), 491-533.

Grinblatt, M. and Keloharju, M.: 2000, The Investment Behavior and Performance of Various Investor Types: A Study of Finland's Unique Data Set, Journal of Financial Economics 55, 43-67.

Grinblatt, M. and Keloharju, M.: 2001, How Distance, Language, and Culture Influence Stockholdings and Trades, Journal of Finance 56, 1053-1073.

Grinblatt, M., Keloharju, M. and Linnainmaa, J.: 2012, IQ and Stock Market Participation, Journal of Finance 104(2), 339-362.

Guiso, L., Haliassos, M. and Jappelli, T.: 2003, Household Stockholding in Europe: Where Do We Stand and Where Do We Go?, Economic Policy 18, 123-170.

Guiso, L. and Jappelli, T.: 2005, Awareness and Stock Market Participation, Review of Finance 9(4), 537-567.

Guiso, L., Sapienza, P. and Zingales, L.: 2008, Trusting the Stock Market, Journal of Finance 63(6), 2557-2600.

Guner, N. and Knowles, J.: 2004, Marital Instability and the Distribution of Wealth, Working paper, Universitat Autonoma de Barcelona.

Heckman, J., LaLonde, R. and Smith, J.: 1999, The Economics and Econometrics of Active Labor Market Programs, in O. Ashenfelter and D. Card (eds), Handbook of Labor Economics, Elsevier, Amsterdam.

Hess, G.: 2004, Marriage and Consumption Insurance: What?s Love Got to Do with It?, Journal of Political Economy 112(2), 290-318.

Hong, H., Kubik, J. D. and Stein, J. C.: 2004, Social Interaction and Stock-Market Participation, Journal of Finance 59(1), 137-164.

Jianakoplos, N. A. and Bernasek, A.: 1998, Are Women more Risk Averse?, Economic Inquiry 36, 620-630. 
Love, D. A.: 2010, The Effects of Marital Status and Children on Savings and Portfolio Choice, Review of Financial Studes 23, 385-432.

Massa, M. and Simonov, A.: 2005, Behavioral Biases and Investment, Review of Finance 9(4), 483-507.

Mincer, J. A.: 1974, Schooling, Experience, and Earnings, Columbia University Press, New York.

Nielsen, H. S. and Svarer, M.: 2009, Educational Homogamy: How Much is Oppertunities, Journal of Human Resources 44(4), 1066-1086.

Sunden, A. E. and Surette, B. J.: 1998, Gender Differences in the Allocation of Assets in Retirement Savings Plans, American Economic Review 88(2), 207-211.

Svarer, M.: 2004, Is Your Love in Vain? Another Look at Premarital Cohabitation and Divorce, Journal of Human Resources 39(2), 523-536.

Thornqvist, T. and Vardardottir, A.: 2012, Bargaining Over Risk. The Impact of Bargaining Power on the Riskiness of Household Portfolios, Working paper, Stockholm School of Economics.

Van Rooij, M., Lusardi, A. and Alessie, R.: 2007, Financial Literacy and Stock Market Participation, SSRN Working Paper.

Viceira, L. M.: 2001, Optimal Portfolio Choice for Long-Horizon Investors with Nontradable Labor Income, Journal of Finance 56(2), 433-470.

Vissing-Jorgensen, A.: 2004, Perspectives on Behavioral Finance: Does Irrationality Disappear with Wealth? Evidence from Expectations and Actions, in M. Gertler and K. Rogoff (eds), NBER Macroeconomics Annuals, MIT Press.

Weiss, Y.: 1997, The formation and dissolution of families: Why marry? Who marries whom? And what happens upon divorce, in M.R.Rosenzweig and O. Stark (eds), Handbook of Population and Family Economics, Elsevier, Amsterdam, chapter 3, pp. $81-123$.

Zagorsky, J.: 2005, Marriage and divorces impact on wealth, Journal of Sociology 41(4), 406-424. 


\section{A Appendix}

\section{Definition of Marriage}

The definition of married investors includes both lawfully married and unmarried cohabiting couples. Getting married thus includes both getting lawfully married and moving in together and it does not include couples that already live together that get lawfully married. ${ }^{12}$

Svarer (2004) finds that there is no negative selection into cohabiting, rather cohabiting is considered a trial marriage before actual marriage. Svarer (2004), like us, studies Danish data, i.e. his conclusion that there are no big differences between cohabiting and marriage should be transferable to our setting. As a robustness check, though, we also directly estimate the effects on stock market participation and risky share when investors change civil status from cohabiting to lawfully married. We find no significant effects on investment behavior. ${ }^{13}$ Thus, empirically it is also unimportant to distinguish between cohabiting and lawfully married investors.

\section{Definition of Divorce}

Similarly, getting divorced includes both divorce of lawfully married individuals and cohabiting individuals moving apart.

The legislation for the division of property (meaning belongings in general, not just real estate property) differs slightly when a legal marriage ends with a divorce and when a cohabiting couple move apart. Cohabiting couples can issue a simple legal document that ensures that their cohabitation has the same legal status as if they were legally married couples. In both cases, each partner takes his or her own property out of the relationship. Joint ownership has to be explicitly stated to apply for cohabiting couples. Otherwise, the signatory is seen as the owner even if both partners are payers and users. In contrast, implicit joint ownership is valid for legally married couples, here the payers and users not the signatories are the owners.

The effects on financial investments from ending cohabitation are cleaner than those from ending lawful marriage due to the differences regarding the rules for division of

\footnotetext{
${ }^{12}$ We delete individuals who make more than one marital status transition in the sample period. Consequently, the control groups consist of individuals who are single and married, respectively, during the whole sample period.

${ }^{13}$ We apply the same DID estimation strategy as in the remainder of the paper. Here the investors making the civil status transition from being unmarried cohabiting to being lawfully married are benchmarked by those staying unmarried cohabiting throughout the sample period.
} 
property.

It is not possible to directly test the difference between ending cohabitation and ending lawful marriage in the same way, as only very few change civil status from lawfully married to cohabiting.

\section{Tax Rules}

If there are tax benefits associated with one part of a married couple owning the financial assets, the holdings of married men and women might not reflect the "true" preferences towards risk of each individual. However, there is no tax-advantage from "transferring" ownerships of stocks to the partner in Denmark, as taxation of financial income is done at the household level for both married and cohabiting couples. For financial income there is a basic allowance below which it is tax free. The basic allowance is shared by household partners and for a household of two adults the basic allowance is twice that of a household of one adult. The taxation above the basic allowance occurs at a flat rate.

\section{Changes in Legislation}

During the period under investigation there are no significant changes in the legislation related to taxation of financial income and related to marriage and divorce. Thus, there are unfortunately no such legislation changes to be exploited as exogenous variation in the costs and benefits of marriage and divorce. 
Table 1: Expected and Estimated Effects on Exposures to Risky Assets.

\begin{tabular}{|c|c|c|c|c|}
\hline \multirow{2}{*}{ Expected Effects } & \multicolumn{2}{|c|}{ Marriage } & \multicolumn{2}{|c|}{ Divorce } \\
\hline & Men & Women & Men & Women \\
\hline Economic resources & + & + & - & - \\
\hline Risk aversion & - & + & + & - \\
\hline \multirow[t]{2}{*}{ Estimated Effects } & \multicolumn{2}{|c|}{ Marriage } & \multicolumn{2}{|c|}{ Divorce } \\
\hline & Men & Women & Men & Women \\
\hline Stock market participation & + & + & - & + \\
\hline Risky share & - & None & + & - \\
\hline
\end{tabular}

The top panel shows the sign of the expected effects due to economic resources and risk aversion upon investors' stock holdings due to marriage and divorce for men and women separately. The bottom panel shows the estimated signs of the stock market participation and the risky share due to marriage and divorce for men and women separately. 
Table 2: Summary Statistics

\begin{tabular}{|c|c|c|c|c|c|c|c|c|}
\hline \multirow[b]{2}{*}{ Variable } & \multicolumn{4}{|c|}{ Men } & \multicolumn{4}{|c|}{ Women } \\
\hline & $\begin{array}{l}\text { Always } \\
\text { single }\end{array}$ & Marriage & $\begin{array}{l}\text { Always } \\
\text { married }\end{array}$ & Divorce & $\begin{array}{c}\text { Always } \\
\text { single }\end{array}$ & Marriage & $\begin{array}{l}\text { Always } \\
\text { married }\end{array}$ & Divorce \\
\hline$\overline{\mathrm{I}}[$ Stock market participation] & $\begin{array}{c}20.0 \% \\
(40.0 \%)\end{array}$ & $\begin{array}{c}20.1 \% \\
(40.1 \%)\end{array}$ & $\begin{array}{c}29.6 \% \\
(45.6 \%)\end{array}$ & $\begin{array}{c}19.9 \% \\
(39.9 \%)\end{array}$ & $\begin{array}{c}18.4 \% \\
(38.7 \%)\end{array}$ & $\begin{array}{c}16.6 \% \\
(37.2 \%)\end{array}$ & $\begin{array}{c}22.8 \% \\
(41.9 \%)\end{array}$ & $\begin{array}{c}18.7 \% \\
(39.1 \%)\end{array}$ \\
\hline Stock value (DKK) & $\begin{array}{c}17,146 \\
(159,668)\end{array}$ & $\begin{array}{c}10,486 \\
(90,052)\end{array}$ & $\begin{array}{c}28,900 \\
(960,619)\end{array}$ & $\begin{array}{c}13,733 \\
(116,830)\end{array}$ & $\begin{array}{c}23,554 \\
(820,017)\end{array}$ & $\begin{array}{c}8,797 \\
(145,070)\end{array}$ & $\begin{array}{c}13,611 \\
(417,589)\end{array}$ & $\begin{array}{c}12,412 \\
(108,161)\end{array}$ \\
\hline Risky share & $\begin{array}{c}33.2 \% \\
(31.6 \%)\end{array}$ & $\begin{array}{l}33.8 \% \\
(32.1 \%)\end{array}$ & $\begin{array}{l}33.9 \% \\
(32.1 \%)\end{array}$ & $\begin{array}{c}34.2 \% \\
(32.1 \%)\end{array}$ & $\begin{array}{c}30.1 \% \\
(29.8 \%)\end{array}$ & $\begin{array}{c}29.6 \% \\
(30.1 \%)\end{array}$ & $\begin{array}{c}33.9 \% \\
(32.3 \%)\end{array}$ & $\begin{array}{c}30.4 \% \\
(31.2 \%)\end{array}$ \\
\hline Noncapital income (DKK) & $\begin{array}{c}220,490 \\
(153,132)\end{array}$ & $\begin{array}{c}265,872 \\
(179,825)\end{array}$ & $\begin{array}{c}387,376 \\
(353,524)\end{array}$ & $\begin{array}{c}310,095 \\
(223,451)\end{array}$ & $\begin{array}{c}208,811 \\
(124,285)\end{array}$ & $\begin{array}{c}197,781 \\
(126,625)\end{array}$ & $\begin{array}{c}239,330 \\
(120,280)\end{array}$ & $\begin{array}{c}235,898 \\
(344,903)\end{array}$ \\
\hline Financial wealth (DKK) & $\begin{array}{c}102,744 \\
(536,248)\end{array}$ & $\begin{array}{c}82,718 \\
(801,073)\end{array}$ & $\begin{array}{c}183,167 \\
(4,379,610)\end{array}$ & $\begin{array}{c}97,052 \\
(736,946)\end{array}$ & $\begin{array}{c}120,178 \\
(1,332,378)\end{array}$ & $\begin{array}{c}68,055 \\
(450,503)\end{array}$ & $\begin{array}{c}85,292 \\
(754,636)\end{array}$ & $\begin{array}{c}113,301 \\
(784,820)\end{array}$ \\
\hline $\mathrm{I}[$ Children $]$ & $\begin{array}{c}1.7 \% \\
(12.9 \%)\end{array}$ & $\begin{array}{c}19.7 \% \\
(39.9 \%)\end{array}$ & $\begin{array}{c}51.2 \% \\
(50.0 \%)\end{array}$ & $\begin{array}{c}28.8 \% \\
(45.3 \%)\end{array}$ & $\begin{array}{l}18.0 \% \\
(38.4 \%)\end{array}$ & $\begin{array}{c}26.1 \% \\
(43.9 \%)\end{array}$ & $\begin{array}{c}46.8 \% \\
(49.9 \%)\end{array}$ & $\begin{array}{c}44.6 \% \\
(49.7 \%)\end{array}$ \\
\hline Age & $\begin{array}{c}37.0 \\
(11.9)\end{array}$ & $\begin{array}{l}32.1 \\
(9.9)\end{array}$ & $\begin{array}{l}45.8 \\
(9.0)\end{array}$ & $\begin{array}{l}40.8 \\
(9.8)\end{array}$ & $\begin{array}{c}40.2 \\
(12.3)\end{array}$ & $\begin{array}{c}31.6 \\
(10.2)\end{array}$ & $\begin{array}{l}44.6 \\
(9.5)\end{array}$ & $\begin{array}{c}40.8 \\
(10.7)\end{array}$ \\
\hline Length of education & $\begin{array}{l}11.3 \\
(2.7)\end{array}$ & $\begin{array}{l}12.0 \\
(2.5)\end{array}$ & $\begin{array}{l}12.2 \\
(3.0)\end{array}$ & $\begin{array}{l}11.8 \\
(2.8)\end{array}$ & $\begin{array}{l}11.8 \\
(3.0)\end{array}$ & $\begin{array}{l}12.2 \\
(2.6)\end{array}$ & $\begin{array}{l}11.9 \\
(3.0)\end{array}$ & $\begin{array}{l}11.9 \\
(3.0)\end{array}$ \\
\hline $\mathrm{I}[$ Economist $]$ & $\begin{array}{c}3.0 \% \\
(16.9 \%)\end{array}$ & $\begin{array}{c}4.1 \% \\
(19.9 \%)\end{array}$ & $\begin{array}{c}4.6 \% \\
(20.9 \%)\end{array}$ & $\begin{array}{c}3.4 \% \\
(18.2 \%)\end{array}$ & $\begin{array}{c}2.5 \% \\
(15.7 \%)\end{array}$ & $\begin{array}{c}3.3 \% \\
(18.0 \%)\end{array}$ & $\begin{array}{c}3.5 \% \\
(18.4 \%)\end{array}$ & $\begin{array}{c}3.1 \% \\
(17.2 \%)\end{array}$ \\
\hline Observations & 212,113 & 77,464 & 406,957 & 41,092 & 157,333 & 66,377 & 443,209 & 47,455 \\
\hline
\end{tabular}

The table shows the average/proportion and the standard deviation in parentheses for the relevant variables for investors dividend into groups according to gender and marital status. 


\section{Table 3: Stock Market Participation}

Additional explanatory variables

Socioeconomic

Log noncapital income

Financial wealth

\section{Men}

DID estimator

Std. error (clustering)

Probit DID estimator (marg effect) Std. error (probit)

Observations

\section{Women}

DID estimator

Std. error (OLS)

Std. error (clustering)

Probit DID estimator (marg effect)

Std. error (probit)

Observations
Std. error (OLS)

\begin{tabular}{cccc}
\multicolumn{3}{c}{ Marriage } \\
\hline (i) & (ii) & (iii) & $($ iv $)$ \\
& + & + & + \\
& + & +
\end{tabular}

(iv)

$+$

$+$

$\begin{array}{ccccccccc}0.011 & 0.011 & 0.005 & 0.006 & -0.013 & -0.016 & -0.012 & -0.012 \\ (0.003) * * & (0.003) * * & (0.003) & (0.003) * & (0.005) * * & (0.005) * * & (0.005) * * & (0.005) * * \\ (0.004) * & (0.003) * * & (0.003) & (0.003) * & (0.003) * * & (0.004) * * & (0.005) * & (0.000) * * \\ 0.011 & 0.011 & 0.005 & 0.009 & -0.011 & -0.013 & -0.011 & -0.012 \\ (0.003) * * & (0.003) * * & (0.003) & (0.003) * & (0.005) * & (0.005) * * & (0.005) * & (0.005) *\end{array}$

289,065

$279,171 \quad 276,986$

276,986

447,142

439,078

437,462

437,462

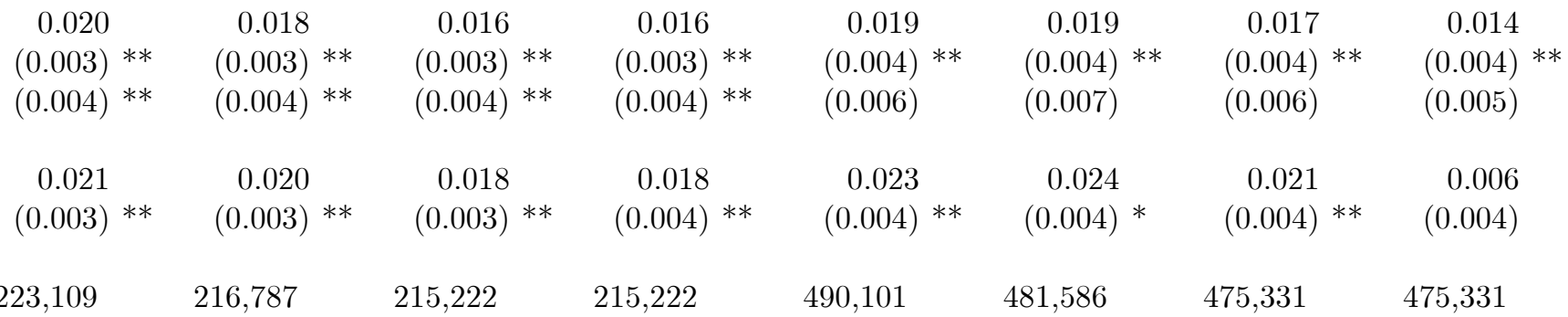

Notes: The table shows the DID estimates for the stock market participation when investors change marital status. OLS, clustering, and probit standard errors are shown. $* / * *$ indicates significance at the $5 \% / 1 \%$ level of significance. 


\section{Table 4: Risky Share}

Additional explanatory variables

Socioeconomic

Log noncapital income

Financial wealth

\section{Men}

DID estimator

Std. error (OLS)

Std. error (clustering)

\section{Tobit DID}

Std. error (tobit)

Coefficient to financial wealth (millions)

Observations

\section{Women}

DID estimator

Std. error (OLS)

Std. error (clustering)

\section{Tobit DID}

Std. error (tobit)

Coefficient to financial wealth (millions)

\section{Observations}

\begin{tabular}{ccc} 
& \multicolumn{2}{c}{ Marriage } \\
\hline (i) & (ii) & (iii) \\
& + & + \\
& & +
\end{tabular}

\begin{tabular}{|c|c|c|c|c|c|c|c|}
\hline $\begin{array}{r}0.000 \\
(0.005) \\
(0.003)\end{array}$ & $\begin{array}{c}-0.014 \\
(0.006) * \\
(0.004) * *\end{array}$ & $\begin{array}{l}-0.012 \\
(0.006) \\
(0.004)\end{array}$ & $\begin{array}{c}-0.013 \\
(0.006) * \\
(0.004) * *\end{array}$ & $\begin{array}{c}0.010 \\
(0.007) \\
(0.006) *\end{array}$ & $\begin{array}{c}0.018 \\
(0.007) * \\
(0.008) * *\end{array}$ & $\begin{array}{c}0.018 \\
(0.007) * \\
(0.008) * *\end{array}$ & $\begin{array}{c}0.018 \\
(0.007) * \\
(0.008)\end{array}$ \\
\hline $\begin{array}{r}0.000 \\
(0.005)\end{array}$ & $\begin{array}{c}-0.009 \\
(0.006)\end{array}$ & $\begin{array}{c}-0.008 \\
(0.006)\end{array}$ & $\begin{array}{c}-0.008 \\
(0.006) * \\
-0.012 * *\end{array}$ & $\begin{array}{r}0.006 \\
(0.007)\end{array}$ & $\begin{array}{c}0.012 \\
(0.007) *\end{array}$ & $\begin{array}{c}0.012 \\
(0.007) *\end{array}$ & $\begin{array}{c}0.012 \\
(0.007)\end{array}$ * \\
\hline, 792 & 57,138 & 56,860 & 56,860 & 128,354 & 127,149 & 126,826 & 126,826 \\
\hline
\end{tabular}

$\begin{array}{rrrrrrrr}0.022 & 0.010 & 0.010 & 0.010 & -0.044 & -0.042 & -0.042 & -0.040 \\ (0.006) * * & (0.006) & (0.006) & (0.006) & (0.007) * * & (0.007) * * & (0.007) * * & (0.007) * * \\ (0.007) * * & (0.006) & (0.006) & (0.006) & (0.016) & (0.015) & (0.015) & (0.014) \\ & & & & & \\ 0.014 & 0.006 & 0.007 & 0.007 & -0.029 & -0.027 & -0.027 & -0.026 \\ (0.006) * * & (0.006) & (0.006) & (0.006) & (0.007) * * & (0.007) * * & (0.007) * * & (0.007) * * \\ & & & -0.001 * * & & & & -0.007 * *\end{array}$

$39,342 \quad 39,135$

(iv)
+
+
+

$+$

(i)

(ii)

(ii)

Divorce

$+$

$\begin{array}{cc}\text { (iii) } & \text { (iv) } \\ + & + \\ + & +\end{array}$

\section{$+$}

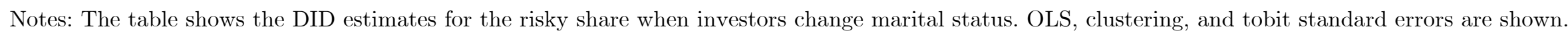
$* / * *$ indicates significance at the $5 \% / 1 \%$ level of significance. 
Table 5: Stock Market Participation - Household Income Correlation

Additional explanatory variables

Socioeconomic

Log noncapital income

Financial wealth

\section{Men}

I[marriage/divorce]

$\mathrm{I}[\text { marriage/divorce }]^{*}$ After

I[marriage/divorce $]^{*}$ After*Correlation

Correlation

Observations

\section{Women}

I[marriage/divorce]

I[marriage/divorce $]^{*}$ After

I[marriage/divorce $]^{*}$ After ${ }^{*}$ Correlation

Correlation

Observations

\begin{tabular}{ccc}
\multicolumn{3}{c}{ Marriage } \\
\hline (i) & (ii) & (iii) \\
& + & + \\
& & +
\end{tabular}

(iv)

+
+
+

$+$

$\begin{array}{rrrr}-0.003 & -0.001 & -0.010 * * & -0.010 \\ 0.038 * * & 0.038 * * & 0.036 * * & 0.038 \\ -0.037 * * & -0.037 * * & -0.041 * * & -0.041 \\ -0.004 & -0.003 & -0.008 & -0.007 \\ 289,060 & 279,166 & 276,981 & 276,981\end{array}$

$\begin{array}{rr}-0.028 * * & 0.004 \\ 0.046 * * & 0.013 \\ -0.039 * * & 0.005 \\ 0.001 & 0.004 \\ 223,109 & 216.787\end{array}$

Divorce

(ii)

$\begin{array}{cc}\text { (iii) } & \text { (iv) } \\ + & + \\ + & + \\ & +\end{array}$

$\begin{array}{rrcc}-0.082^{* *} & -0.054^{* *} & -0.035 * * & -0.035 * * \\ -0.065 * * & -0.055^{* *} & -0.029 * & -0.029 * \\ 0.110^{* *} & 0.050 * * & 0.030 & 0.030 \\ 0.050^{* *} & 0.004 & 0.009 * & 0.009 \text { ** } \\ 446,940 & 438,901 & 437,290 & 437,290\end{array}$

$446,940 \quad 438,901$

$\begin{array}{cc}-0.049 * * & -0.022 * * \\ -0.010 & -0.022 \\ 0.036 * & 0.057 * * \\ -0.007 * & -0.001 \\ 489,910 & 481,411\end{array}$

$\begin{array}{ll}-0.022^{* *} & -0.023^{* *} \\ -0.019 & -0.017 \\ 0.047^{* *} & 0.043^{* *} \\ -0.005 & -0.003 \\ 475,165 & 475,165\end{array}$

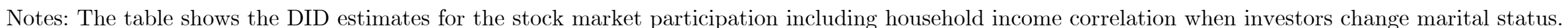
OLS standard errors are shown. */** indicates significance at the 5\%/1\% level of significance. 
Table 6: Risky Share - Household Income Correlation

Additional explanatory variables

Socioeconomic

Log noncapital income

Financial wealth

\section{Men}

I[marriage/divorce]

$\mathrm{I}[\text { marriage/divorce }]^{*}$ After

I[marriage/divorce $]^{*}$ After ${ }^{*}$ Correlation

Correlation

Observations

\section{Women}

$\mathrm{I}[$ marriage/divorce

$\mathrm{I}[\text { marriage/divorce }]^{*}$ After

I $[\text { marriage/divorce }]^{*}$ After* Correlation

Correlation

Observations

\begin{tabular}{ccc}
\multicolumn{3}{c}{ Marriage } \\
\hline (i) & (ii) & (iii) \\
& + & + \\
& & +
\end{tabular}

$\begin{array}{rrrrrrrr}0.009 * & 0.009 & 0.011 * & 0.011 * & -0.008 & -0.004 & -0.004 & -0.004 \\ 0.005 & -0.019 & -0.019 & -0.020 & 0.049 * & 0.066 * * & 0.063 * * & 0.063 * * \\ 0.003 & 0.025 & 0.026 & 0.026 & -0.080 * * & -0.076 * * & -0.072 * & -0.073 * \\ -0.016 & -0.026 * & -0.024 * & -0.023 * & -0.034 * * & -0.013 * * & -0.013 * * & -0.014 * * \\ 57,792 & 57,138 & 56,860 & 56,860 & 128,323 & 127,118 & 126,798 & 126,798\end{array}$

$\begin{array}{rrrrrrrr}-0.007 & -0.004 & -0.002 & -0.003 & -0.015 * * & -0.013 * * & -0.012 * & -0.011 * \\ 0.034 * & 0.021 & 0.021 & 0.021 & -0.029 & -0.024 & -0.025 & -0.024 \\ -0.004 & 0.003 & 0.002 & 0.002 & -0.024 & -0.024 & -0.022 & -0.022 \\ -0.020 & -0.026 * & -0.025 * & -0.025 * & -0.003 & 0.001 & 0.002 & 0.001 \\ 39,799 & 39,342 & 39,135 & 39,135 & 109,672 & 108,871 & 107,785 & 107,785\end{array}$

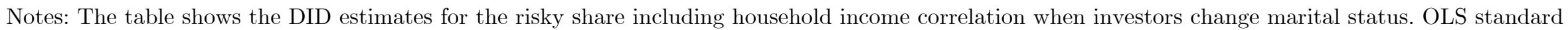
errors are shown. $* / * *$ indicates significance at the $5 \% / 1 \%$ level of significance. 


\section{Figure 1: Stock Market Participation}

a. Men, marriage

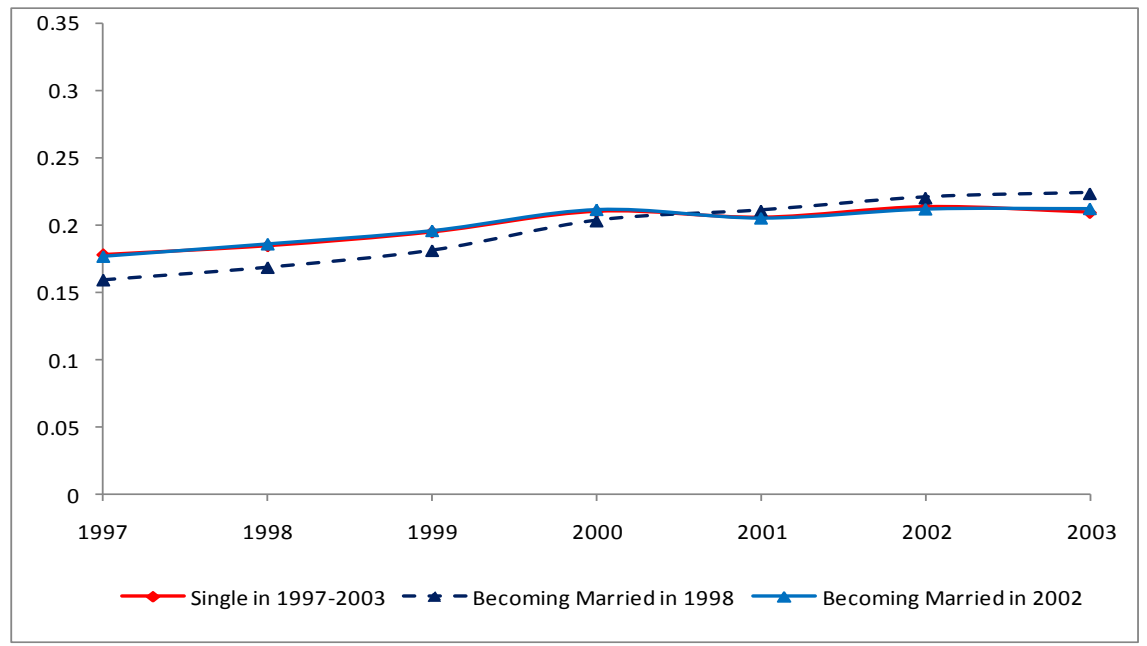

c. Men, divorce

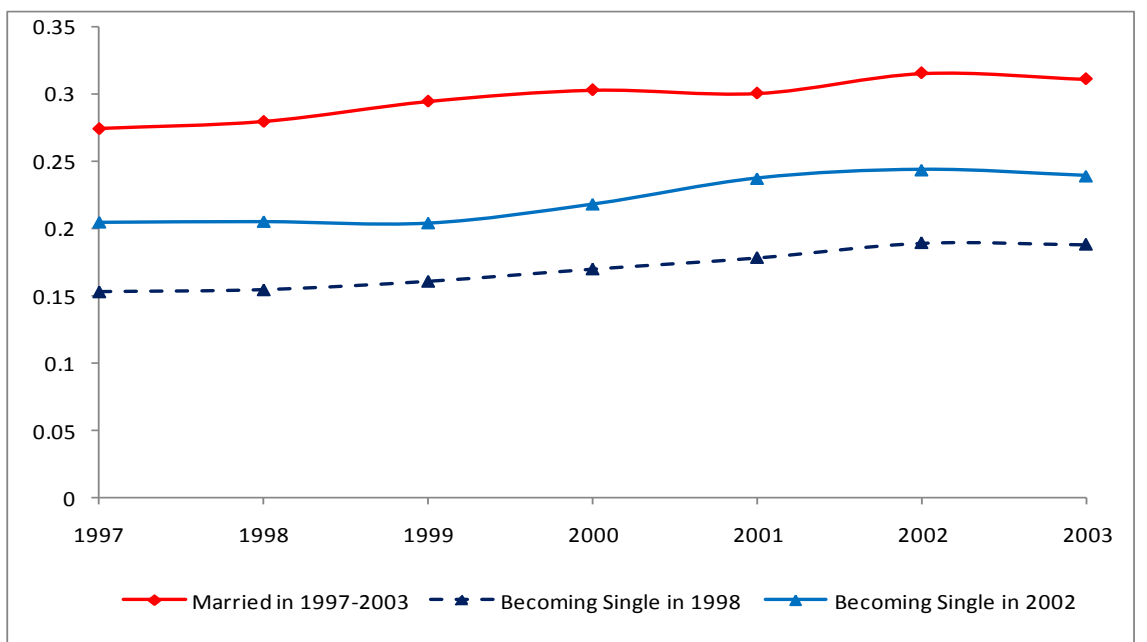

b. Women, marriage

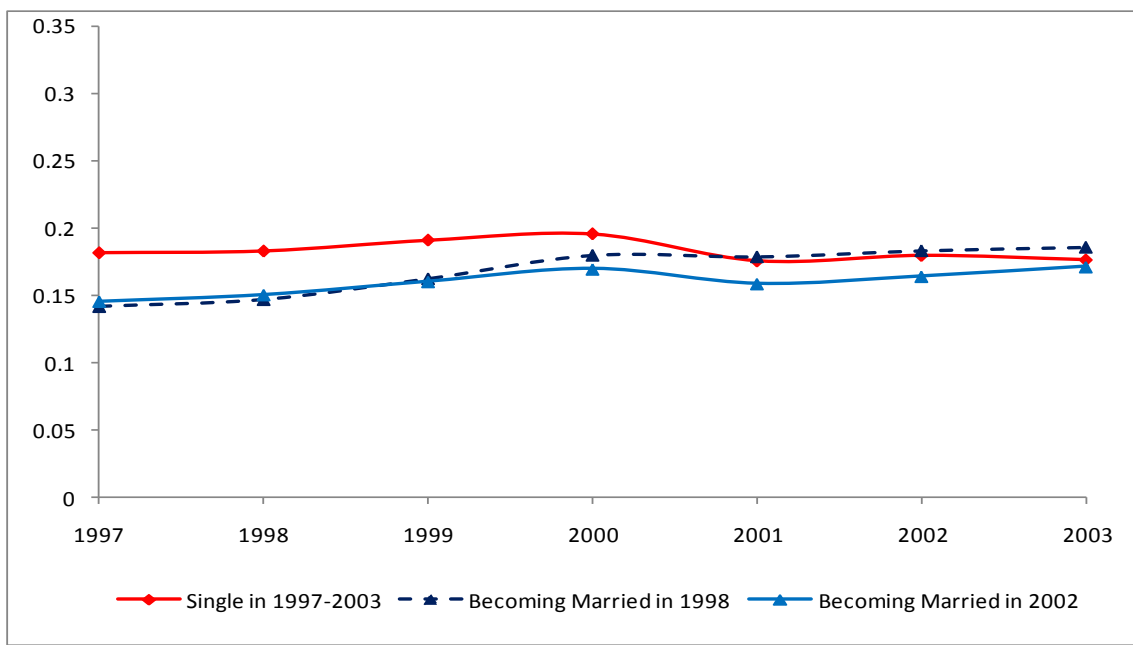

d. Women, divorce

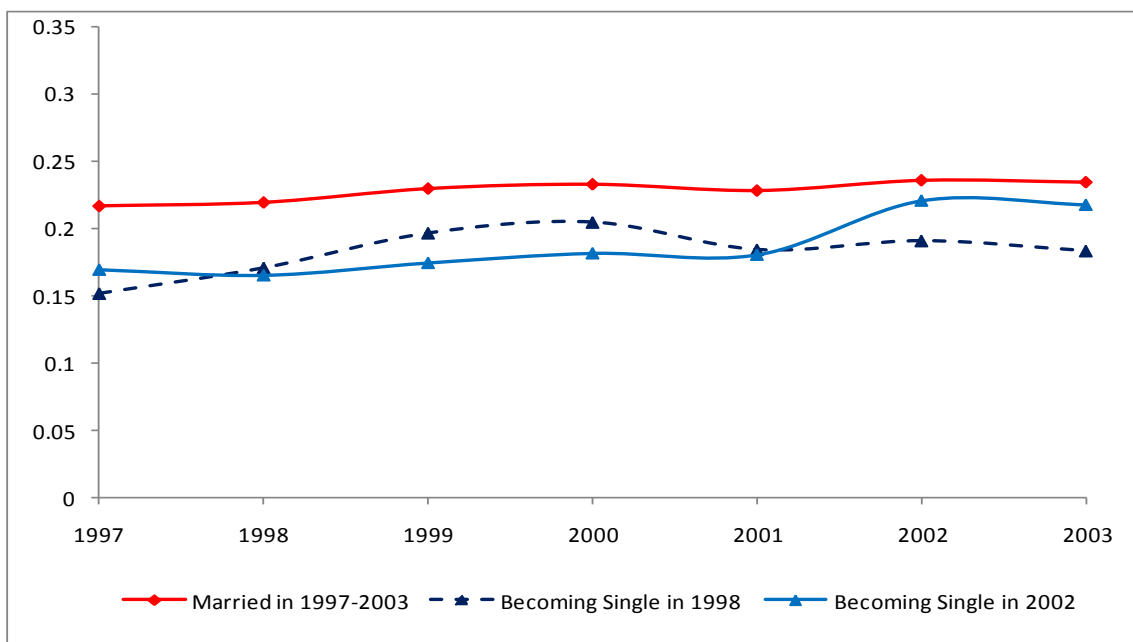




\section{Figure 2: Risky Share}

a. Men, marriage

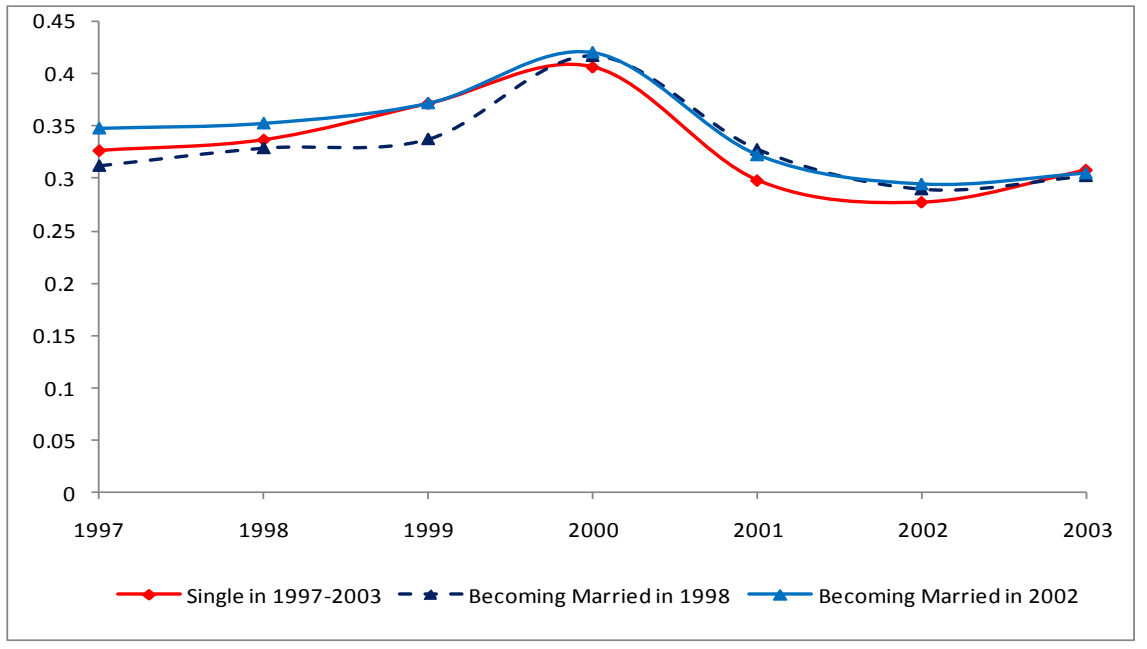

c. Men, divorce

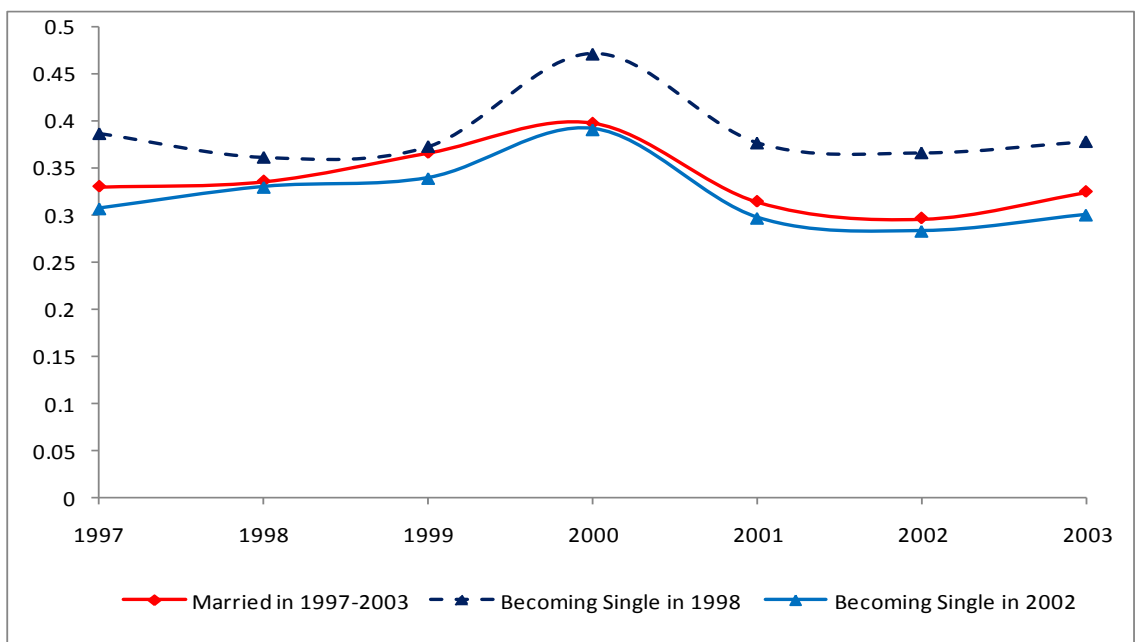

b. Women, marriage

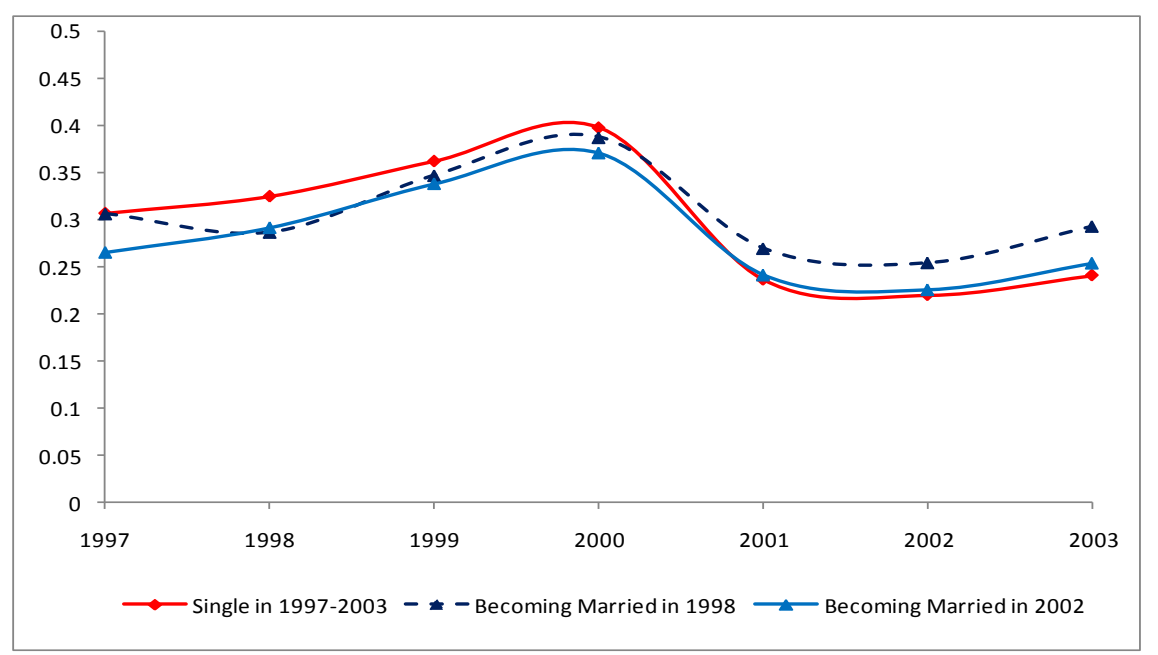

d. Women, divorce

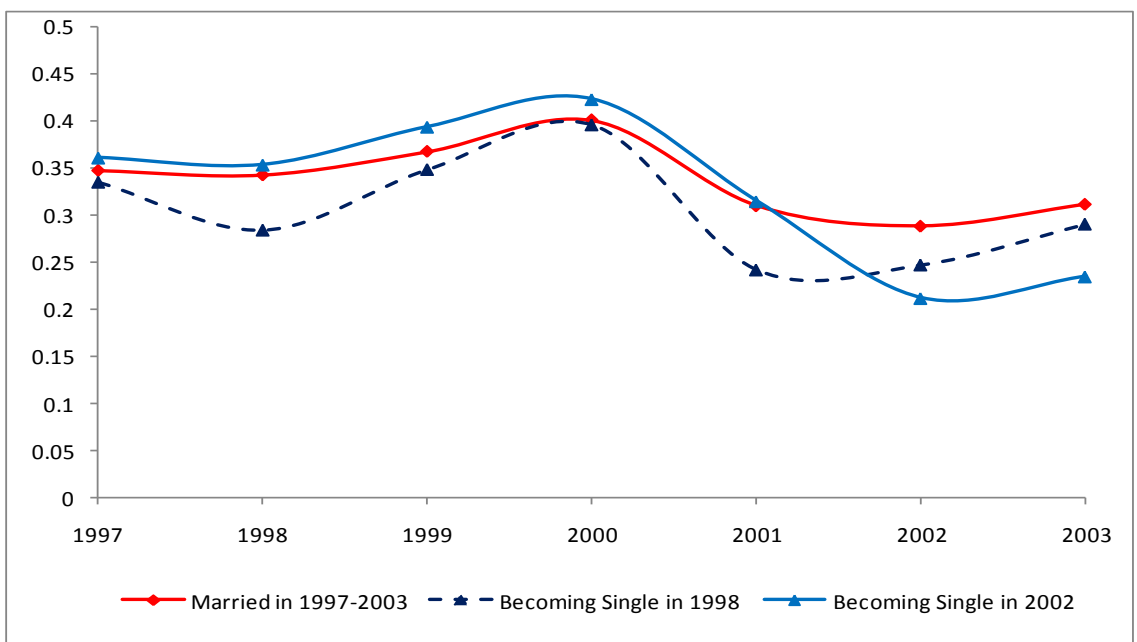

